Cranial Computerized Tomography. Edited by W. LANKSCH and E. KAZNER. 1976. Pp. 478, figs, tables, refs. Springer Verlag, Berlin (DM78)

This book is a collection of papers read at the Third Internation Symposium on Computerised Tomography held in Munich in June 1976. Most of the contributors are from Germany and Switzerland, with a few invited guests from other continental European countries and the United States.

The first section, on physical principles, is clear, well illustrated, and forms an excellent introduction for clinicians wishing to familiarise themselves with basic aspects of the technique. There is also a good section on new technical developments. In the other eight sections most anatomical and pathological areas are covered. The standard of the individual papers is generally high, and the weaker articles probably reflect the relative inexperience of the authors. The sections on neuropaediatrics, brain atrophy-epilepsy-demyelinating and degenerative diseases, and brain oedema make interesting and informative reading.

In general, the width of material covered makes it a useful guide for those clinicians wishing to either acquaint themselves with the technique or to have as a reference volume.

D. TAYLOR

Fison's Retinal Detachment Surgery. By A. LIM SIEw MING. 1977. Pp. 88, figs. P.G. Medical Books, Singapore (No price)

This is a very good book because it has a clear purpose which it fulfils admirably. That purpose is to supply a practical guide to the management of retinal detachment. It is clearly written in a concise form with many short headings so that specific points can easily be discovered. Many excellent colour illustrations and relevant diagrams are so well integrated with the text that the information imparted is more practical than found in many longer books. The author speaks from wide personal experience; his style is therefore didactic rather than scholastic and personal rather than academic-an approach that is exactly correct for a handbook on retinal surgery.

The book is divided into ten chapters: Techniques of Examination and the Binocular Indirect Ophthalmoscope; Scientific Basis of Retinal Detachment Surgery; Cryotherapy, Diathermy and Photocoagulation; Local Plombage and Encircling Techniques; Drainage of Subretinal Fluid; Prophylaxis; Special Problems; Vitreous and Vitreous Surgery; Surgical Complications, Avoidance and Treatment, Recurrence of Detachment; and Postoperative Management and Follow-up.

Such a publication demands good team work, and the editor must be given due credit for the excellent layout of the book. It is a hallmark of the author's philosophy in running a specialist department that the chief should not attempt to maintain a monopoly but give his juniors their heads. This book is based on courses in retinal detachment surgery, originally delivered by his unit in London. It is typical of the author's generosity that in the preface he refers to his registrars who initiated and planned these courses.

R. K. BLACH

Current Contents in Cataract Surgery. Selected Proceedings of the 4th Biennial Cataract Surgical Congress. 1977. Pp. 672, figs, tables, refs. Mosby, St. Louis (London, Kimpton) $(£ 40 \cdot 25)$

In the past 6 years there have been radical changes in the management of cataract. New techniques, such as phacoemulsification, lens fragmentation and aspiration, anterior vitrectomy, and intraocular lenses, have greatly increased the range of cataract surgery. This book consists of selected papers and discussions of the Fourth Biennial Cataract Surgical Congress, and the views of the leading American surgeons on a wide range of these newer techniques and of the perennial problems associated with surgery of the lens are presented in a colloquial but very readable form.

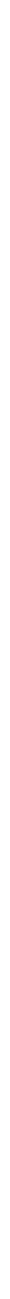

\title{
Obituary
}

\section{E. K. R. Thomas, MB, ChB, FRCSEd, DOMS, 1899-1977}

Kenneth Roy Thomas, who died on 6 July, was born at Llanybyther in 1899, and graduated in medicine at Edinburgh in 1921. In 1924 he was appointed ophthalmic surgeon to Swansea General and Eye Hospital, a post which he held until 1964. He was secretary of the Swansea Division of the BMA from 1929 to 1933 and chairman from 1938 to 1941. In 1962 he was made a Fellow of the BMA. He was a member of the Oxford Ophthalmological Congress and a past president of the Western Society and the Welsh Edinburgh Graduates Association. He was a past president of the Carmarthenshire Society and a member of the Swansea University College Council. He is survived by his wife, Gwyneth, and by his son.

\section{Notes}

\section{1th Hellenic Congress of Ophthalmology}

\section{5-18 June 1978}

The Congress will take place in Chalkidiki (Kassandra peninsula), Greece, on 15 to 18 June 1978. Its subject will be 'Ocular Tumours'. Simultaneous translation in
Greek, English, French, and German. Further details from 11th Hellenic Congress of Ophthalmology, PO Box 497, Thessaloniki, Greece. 